\title{
INTOLERÂNCIA RELIGIOSA E A DEMONIZAÇÃO DE RELIGIÕES DE MATRIZ AFRICANA NA "PANDEMÔNIA"
}

Religious Intolerance and Demonization of African Source Religions at "Pademonia"

Maycon Rodrigo da Silveira Torres ${ }^{1}$

Natasha Martins ${ }^{2}$

\begin{abstract}
RESUMO
Identifica-se o racismo como problema estrutural da sociedade ao cotejar os casos de violência e preconceito contra as religiões de matrizes africanas no Brasil, $O$ trabalho analisa a intolerância religiosa como reflexo do processo de colonização do país que ainda reflete no comportamento fenomenológico da atualidade pelo processo de demonização de determinadas entidades. Exu é uma das figuras que melhor representa o afastamento imposto sobre as culturas africanas, o que inclusive condiciona sua incompreensão por parte da população brasileira, predominante negra. A demonização desta divindade africana em específico, retrata heranças da moralidade e medos europeus estimulados durante a Idade Média, ligados principalmente à doenças e à sexualidade. Atributos pejorativos a Exu, como "Exu Corona" ou "Pandemônia", indicam processo de demonização de divindades de religião de matriz africana como forma de canalizar angústias sociais para ganhos próprios. $\mathrm{O}$ processo de educação religiosa pode ser importante meio de transformação social pela problematização do contraste entre essência e aparência associados a Exu como forma de resistência.
\end{abstract}

Palavras-chave: Exu; Intolerância; Demônio; Candomblé.

\begin{abstract}
When analyzing the alarming increase in violence and prejudice towards religions of African origin in Brazil, racism as structural social problem is identified. The religious intolerance is part of the country's colonization and still reflects a current phenomenological behavior, expressed by demonization of certain entities. Exu is one of the figures that best represents the imposing distance from African culture, which also conditions his incomprehension on the part of the Brazilian population, predominantly black people. The demonization of this African deity in particular portrays European moralities and fears during the Middle Ages, linked mainly to sexuality. Pejorative attributes to Exu, such as "Exu Corona", indicate the process of demonizing its characteristics in order to deal with social anxiety associated to social context.Education may be an important tool of social transformation by contrasting essence and appearance related to Exu às symbol of resistance.
\end{abstract}

Keywords: Exu; Intolerance; Demon; Candomblé.

\footnotetext{
${ }^{1}$ Psicólogo. Psicanalista. Especialista em Psicanálise e Saúde Mental. Mestre e Doutor em Psicologia/UFF. Professor em Graduação de Psicologia/FAMATH. Coordenador de Pós-Graduação em Fundamentos da Clínica Psicanalítica/FAMATh.

2 Nutricionista.Mestranda em Ciências da Religião/Universidade Lusofona de Humanidades e Tecnologias
} 


\section{Introdução}

O diálogo inter-religioso exige primordialmente boa interlocução, e Exu é a divindade Iorubá da comunicação. Ironicamente, também é ele o mais incompreendido e demonizado dentro do panteão religioso afro-brasileiro. Estima-se que o processo da diáspora africana trouxe para o Brasil cerca de $37 \%$ do total da população de pessoas escravizadas vindas de África para o continente americano durante o período colonial (ELTIS; BEHREND; RICHARDSON, 2000). Na atualidade, compreende-se porque uma grande parcela da população brasileira conserva alguma ascendência africana em sua linhagem genética. Apesar disso, a maior parte dos brasileiros desconhece as raízes culturais africanas, que por sua vez são desvalorizadas, recriminadas e agredidas por parte de alguns religiosos extremistas.

Este tensionamento se reproduz em diferentes esferas sociais e estatais, incluindo a Justiça, ao exemplo da tentativa de proibição por lei do uso de animais em rituais de religiões de matrizes africanas. A formulação de discursos por agentes religiosos de diferentes denominações aciona e legitima a intolerância religiosa em ações estatais (LEISTNER; AGUIAR, 2020). Define-se intolerância como forma de opressão derivada do não reconhecimento da diversidade que compõe uma sociedade, de forma que o outro não é respeitado em atributos que o diferencia dos demais, como a religião (REIS; LOPES, 2017).

Deve-se demarcar que, em 1988, com a Constituição Federal de redemocratização, o Brasil se instituiu como país laico e com liberdade religiosa no sentido de defender a exclusão da influência religiosa em políticas de Estado, na cultura e na educação. Um Estado laico não tem uma religião oficial, permite a convivência entre religiões e credos, além de combater a intolerância religiosa. Até os anos 70 os espaços de práticas da religião afro-brasileira Candomblé sofriam repreensões por parte da polícia, de forma que a intolerância não partia apenas de outras religiões, mas também do próprio Estado (JUNQUEIRA; REIS, 2020).

O diálogo entre religiões possibilita a existência de um ambiente amplamente seguro e garantido para que cada indivíduo e comunidade possam expressar sua fé. A liberdade religiosa só existe quando os direitos humanos não são feridos e os fiéis se sentem confortáveis para fazer suas escolhas. A prática da tolerância religiosa deve ser um dos alicerces dos direitos humanos sustentados pelas iniciativas do Estado democrático. A Declaração sobre a eliminação de todas as formas de intolerância e discriminação fundadas na religião ou nas convicções da Assembleia Geral das Nações Unidas em 1981 serviu como marco norteador de políticas para 
promoção de ações contra a intolerância, porém, ainda encontra resistências no Brasil, especialmente contra às religiões de matrizes africanas (BATISTA et al., 2017).

Ao observar a utilização de termos como "Pandemonia" e "Exu Corona" por parte de membros chefes de igrejas neopentecostais em meio a crise sanitária da Covid-19 causada pelo coronavírus (SARS-CoV-2) entre 2020 e 2021, fez-se uma correlação entre a idéia sobre a figura do demônio, Exu, ignorância religiosa e o papel da educação religiosa. A conexão da figura de Exu ao demônio demonstra grandes equívocos na cultura popular e na visão que as religiões africanas recebem. A falta de contextualização cultural, inicialmente propagada pela Igreja Católica durante o período colonial, julgou e combateu outras religiões conforme os seus próprios dogmas, estigmatizando-as assim, como inferiores e malignas. Os saberes relacionados à cultura africana foram combatidos, muitos foram perdidos, e o fanatismo religioso conseguiu gerar grandes distanciamentos para com estas filosofias na maior parte da população (FERNANDES, 2017).

Este trabalho tem como objetivo discutir o processo de demonização da figura de Exu e elucidar o direito à liberdade religiosa, destacando a importância da aproximação entre as narrativas originárias desta entidade com pessoas de outros segmentos religiosos, principalmente as abraâmicas hegemônicas. A pesquisa de revisão bibliográfica visa dar relevância aos fatores históricos que construíram a imagem demoníaca e promoveram afastamento com a cultura de origem negra e seus reflexos no comportamento racista para com estas religiões no Brasil.

\section{Os domínios de Exu}

Senhor dos caminhos, do caos, da vitalidade, da comunicação, do inseguro, de tudo que está fora da visão e de tantos outros domínios, Exu é uma divindade bastante complexa devido todas qualidades que lhe são atribuídas. Reconhecido por muitos outros nomes como Bará, Malandro, Elegbará e Pombo Gira, está associado aos cultos de Candomblé, Umbanda e de outras religiões de matrizes africanas. Certamente foi ele o orixá que mais recebeu incompreensão e preconceito religioso ao longo da história do Brasil. (PRANDI, 2001). Para o Candomblé, os orixás são entidades em alto grau de evolução, dotados de axé, energia vital e pura presente nos elementos da natureza. Cada orixá rege um determinado conjunto de energias e atributos, assim como adepto dessa religião é regido por um orixá. Mitologicamente, por 
serem puro poder, essas entidades não são duais entre bem ou mal, mas inserem-se em rede de complexidade e diversidade entre si, tais quais os seres humanos (REIS; LOPES, 2017).

O culto de Exu é originário do antigo Daomé, hoje atual Benim, Nigéria e Togo, fazendo parte essencial da ritualística iorubá, ou também chamado, povo Nagô. Sua disseminação no Brasil exige ressaltar alguns pontos que por vezes podem parecer confusos. A palavra Èsù na língua iorubá significa “esfera”, termo o qual identifica bem uma de suas qualidades: a natureza do movimento. Por conseguinte, quando se fala desta divindade, diz-se de uma energia que não está associada à calma, organização ou quietude. Cada região da África, conhecidas no período pré-escravocrata também como nações, possuía rituais e costumes próprios. Destes, os grupos etínico-culturais mais expressivos em solo brasileiro foram os Bantus, Fons e Iorubás (PRANDI, 2002).

A chegada dos cultos africanos nas Américas recebeu influência de outras culturas que ali já estavam, como é o caso das diferentes populações indígenas e do próprio cristianismo popular. Por diferenças entre a flora das Américas e da África, alguns detalhes como o tipo de erva utilizada para determinado rito precisou ser adaptado para que a devoção aos orixás pudesse ser mantida. Também como uma forma de manter proximidade com sua história, grande parte dos sacerdotes buscou, e ainda busca, preservar os costumes religiosos praticados nas religiões o mais fiel possível com suas raízes africanas. A preservação de laços étnicos ocorreu especialmente pelas práticas religiosas em que "os escravos africanos viram-se obrigados a se organizarem, tendo por base semelhanças e alianças que ajudaram a manter suas identidades" (SILVA, 2018, p. 53).

$\mathrm{Na}$ mitologia Iorubá, Exu foi o primeiro dos orixás a receber o sopro de vida. Ele representa a própria energia da criação, de tudo e de todos. A adoração a Exu faz parte da natureza do universo, onde nada pode existir sem sua presença. Como é comum para os povos africanos, a ideia de geração ocorre a partir do caos, que por sua vez, reflete ao vazio, ao nulo e ao encontro dos polos. O caos não era associado ao mau, mas percebido como uma força necessária. Portanto, nessa cosmovisão, Exu é a garantia da vida. "Sua presença está consignada até mesmo no primeiro ato da Criação: sem Exu, nada é possível” (PRANDI, 2001, p. 50).

Exu liga-se ainda a uma divindade cultuada pelo antigo povo Fon, também da região do Daomé, chamada Legba. Para esse grupo, suas entidades sagradas eram chamadas Vodouns, e de fato, Legba e Exu possuem inúmeras semelhanças. Saraiva (2017, p. 12) destaca essa 
correspondência ao descrever Legba como o "anunciador da criação", pois "se tudo está criado, tudo tem uma parte de Legbá, e cada parte do todo também possui Legbá”. Refletir sobre a criação leva os seres humanos a ideia dos inícios, ao útero escuro, mas essa reflexão também indaga ao fim e, neste contexto, a morte. Na visão destas religiões, a morte é um novo início, e sendo assim, também é atribuído a Exu o dever de permitir ou não a passagem da alma para outros planos.

Para populações em que os nascimentos, os partos e a fertilidade eram assuntos que detinham um cuidado fundamental para sobrevivência, nada mais natural que temessem a energia de Exu e ele, por sua vez, tomasse a característica de imponência. Junto disso, essas civilizações receavam ao escuro que ficava para fora de suas casas ou abrigos; afligiam-se com este ambiente inseguro, incontrolável e desconhecido, o caos. Até hoje nos terreiros, locais onde são realizadas as práticas dos cultos aos orixás, é imprescindível a presença de Exu, que por sua vez, possui seu local de resguardo no espaço fora da casa principal. Exu, como mensageiro, possui a função de levar a mensagem às demais entidades, dessa forma, sempre é o primeiro a ser reverenciado nos cultos, e também é o primeiro que come. Vale ressaltar o valor que o alimento detém na ritualística afro-brasileira, onde a divindade assim como os seres humanos necessita se nutrir a partir de preparações que fortalecem seus atributos. De fato, a cozinha, o preparo dos alimentos e a alimentação fazem parte do cerne da relação com o divino e o sagrado. As vertentes religiosas, como Umbanda ou Candomblé, possuem seus rituais intimamente ligados à prática de oferendas, ou seja, para que as energias possam ser alimentadas é preciso antes de tudo dar de comer a Exu (ALVARENGA, 2019).

Segundo Pinto e Freitas (1972, p. 40), nos primeiros cultos de Exu a Otá, assim chamada a imagem do orixá, era feita de "tabatinga virgem, carvão ou toco queimado". As oferendas feitas para Exu buscam evocar suas qualidades que normalmente são de fertilidade, purificação, vitalidade e comunicação com o sagrado. Também os alimentos e presentes preferidos de Exu, aqueles que aumentam suas qualidades essenciais, são carnes, preferencialmente de galo ou bode preto, farofa, óleo de dendê, cachaça ou bebidas alcoólicas fortes, tabaco entre outros.

Na mitologia Iorubá existem várias passagens que contam sobre a natureza faminta de Exu. Filho caçula de Yemanjá e Orunmilá, Exu comia de tudo e tinha uma fome incontrolável. Um dia, comeu todos os animais da aldeia, os cereais, as raízes e as frutas; bebeu toda a cerveja e aguardente, além de todo azeite de dendê. A fome aumentava quanto mais comia. Depois de 
ingeridos todos os alimentos, comeu as árvores e o mar. Com medo de que devorasse o céu, Orunmilá pediu a Ogun que impedisse o irmão. Mesmo após a morte, Exu continuava a comer. O sacerdote de Ifá alertou que o espírito de Exu precisava ter sua fome por atenção saciada e, para evitar novas catástrofes, era necessário, em todas as oferendas, primeiro dar de comer a Exu (PRANDI, 2015).

Como responsável pela comunicação entre os orixás e o mundo dos seres humanos, Exu tem grande importância para a efetividade das consultas oraculares. Nas culturas africanas, os oráculos possuem não só relevância nas questões ligadas a vida da comunidade, como o plantio e colheita, mas também para definições quanto à realização de cada ritual. Um exemplo disso é o jogo de búzios, utilizado como oráculo para, também, identificar a qual Orixá cada indivíduo possui ligação energética direta, e dessa forma, definir qual linha ritual deve obedecer. $\mathrm{O}$ sistema oracular iorubano e daomeano funcionam como um tipo de correio entre os humanos e os orixás. O sacerdote de Ifá, outro exemplo de oráculo utilizado, é procurado para sanar dúvidas através de consultas aos orixás e, "para que o sistema oracular funcione, uma das peças fundamentais é Exu" (NOGUEIRA, 2017, p. 55).

Neste contexto, na percepção cosmogônica, toda atividade que requer comunicação para ter sucesso está sob o domínio de Exu. Comerciantes, diplomatas, professores, telefonistas, todos trabalhariam com a energia desta divindade, e de certa forma, na vida humana, praticamente todas as atividades recaem de uma forma ou de outra na presença do Orixá.

Os símbolos e objetos normalmente associados a Exu são o tridente, a chave e o falo, seu instrumento mágico é chamado $O g o ́$, que é um bastão de madeira talhado no formato de um falo. Por vezes, Exu surge como uma figura engraçada e brincalhona, e por vezes como um ser tenebroso, obscuro e até meio animal.

Delimitar a área de atuação e características de Exu é uma tarefa um tanto complexa. Isto se deve ao fato de que a maioria dos registros por parte de viajantes, principalmente europeus, que tiveram contato com a religião iorubá acabaram atribuindo a esta divindade uma imagem diabólica que, em grande parte, não condizia com a forma como os próprios iorubás o concebiam (NOGUEIRA, 2017, p. 52).

Por fim desta breve descrição sobre Exu, é valoroso ter consciência da complexidade que envolve definir tal divindade, pois Exu é o próprio mistério existencial que constrói a vida e a morte. É ele entre todos os deuses deste panteão que mais se aproxima dos seres humanos. 
Possuindo características puras e cruéis, por onde o homem tem a possibilidade de enxergar como em um espelho, aquilo que de mais belo e feio, existe na humanidade.

\section{A demonização de Exu}

O preconceito com religiões de matrizes africanas tem início ainda no período escravocrata, quando os negros eram reduzidos ao símbolo de inferioridade, de seres selvagens que deveriam ser salvos pela fé cristã hegemônica (NOGUEIRA, 2017). A intolerância, seja ela de qualquer natureza, é um fenômeno que parte de uma inflexibilidade, em que uma pessoa considera sua verdade acima das demais. Na concepção de mundo por parte de muitos europeus no período escravagista, o paganismo era considerado algo extremamente errado, imoral ou fora da lei por estar submetido às escrituras sagradas de Deus e de Jesus. A idolatria ao culto católico foi expressa como intolerância religiosa, com o falso conceito de que era necessário destruir todas as fontes de fé pagãs que existiam e subordinar as populações infiéis aos seus preceitos religiosos.

No caso de Exu, o preconceito institucionalizado foi construído junto de um desconhecimento sobre sua origem, representação e ritualística. A deidade é vista até hoje por grande parte da sociedade como a figura de um ser maligno, um demônio. "Exu, o Diabo, mobiliza e legitima, aos olhos cristãos, o ódio religioso contra a umbanda e o candomblé, corporificado em verdadeira guerra religiosa de evangélicos contra afro-brasileiros" (PRANDI, 2001, p.61).

Silva (2007, p. 213-4) afirma que as supostas evidências de que "as religiões afrobrasileiras são diabólicas decorrem da realização de sacrifícios de animais, transe de possessão por espíritos, culto aos mortos, uso da magia para fazer malefícios etc”. É necessário cuidado com o termo "malefícios", pois indica a valoração da ideia de bom ou mau vinculada diretamente a cosmovisão do indivíduo e dos dogmas a ele ligados. Desta forma, os elementos essenciais para realização da ritualística das religiões de matrizes africanas são sagrados, honrosos e bons aos olhos e na cultura de quem a pratica, porém, são vistos como heresia e ruins aos olhos de quem os julga.

Nas religiões de culto-africano não temos a mesma divisão das religiões judaico-cristãs de bem e o mal, onde nesta cosmologia o caos é sinônimo de ações e pensamentos negativos. Tal representação ressalta os seus "aspectos negativos", tendo vários de seus elementos ressignificados como no caso das religiões neopentecostais como a Igreja Universal do Reino de Deus - IURD, REVISTARELEGENSTHRÉSKEIA - 2021 - UFPR 
que o define com o elemento maligno que deve ser combatido (LEITE, 2018, p.3).

A demonização de Exu vem de um racismo epistêmico que privilegia e valoriza a cultura e o pensar do ser humano, normalmente homem, branco, europeu, que procura distanciar-se do ser selvagem ou primitivo. Exu, por sua vez, é uma divindade que trabalha justamente com elementos comumente oprimidos em religiões abraâmicas, principalmente quanto a sexualidade e os prazeres humanos:

O estranhamento da figura e do papel do Exu e sua proximidade com a vida humana, especialmente a sexualidade e o poder, o tornou um dos focos principais dessa opressão. A diversidade e a complexidade do Exu, embora fosse sua riqueza, era também o que proporcionou a sua demonização. (OLIVEIRA, 2010, p. 37).

Um dos símbolos mais importantes de Exu é o falo. Quando os missionários europeus tiveram contato com este elemento, associaram-no instantaneamente à promiscuidade, sem considerar sua significação relacionada à fertilidade e à vida. Outro elemento que nutriu a associação de Exu com o Diabo, ou demônio, foi a imagem do tridente. Vale ressaltar que as primeiras figuras de Exu ainda na África não aparecem portando um tridente, objeto introduzido posteriormente de forma obscura. Sabe-se da relação deste objeto com o instrumento agrário incorporado às representações artísticas da Idade Média para representar o Diabo. No imaginário das religiões cristãs, este símbolo representa o instrumento de poder dos demoníaco, ainda que nas culturas afro-brasileiras o tridente tenha sido ressignificado para simbolizar a elevação espiritual por meio da sabedoria do equilíbrio, onde a matéria se liga ao divino (BRITO et al., 2019).

Interpretar qualquer símbolo na literalidade, principalmente com um ponto de vista ideológico e religioso, não gera uma contextualização, e neste caso, a literalidade também produz preconceito. A religião se expressa como um elo entre o conjunto de símbolos, seus significados, e os sistemas socioculturais e psicológicos de uma determinada civilização. Já os símbolos são atemporais e falam sobre os mitos de determinada cultura (GEERTZ, 1985).

Uma característica importante da cultura brasileira digna de nota, é a inserção de religiosos cristãos em cargos políticos no legislativo e executivo. A criação de bancadas cristãs e o fortalecimento de discursos, no espaço público, que disseminam posicionamentos que reforçam ideias intolerantes contra grupos de religiões de tradição africana, resultam em outras 
problemáticas ligadas ao tema. "O resultado desses discursos acaba transpondo a realidade discursiva e acaba por gerar ações violentas contra grupos religiosos a ponto de até mesmo ser justificável violências físicas capazes de subtrair vidas” (BATISTA et al., 2017, p.132).

Oliveira (2010) identifica um processo de opressão pela interdição simbólica, que demonstra parcialmente, a significação mítica e cultural com a efetivação de dois processos antagônicos de riqueza simbólica e fragmentação. Assim, ao exemplo da Umbanda, encontrase atributos como Exu Veludo, Exu Tranca-rua, Exu Caveira, os quais delimitam diferentes aptidões de entidades, mas, ao mesmo tempo, junto à demonização, permitem a imposição de máculas e estigmas decorrentes de intolerância religiosa. Exu por ser uma entidade carregada de atributos, tais como comunicação, fertilidade, sexualidade, movimento e voracidade corre o risco de ser interpretado pelo ponto de vista moral como carregado de pecados.

A capacidade de Exu de absorver qualidades é o que também permite que se torne representação do medo na intolerância religiosa. No contexto das medidas de distanciamento social adotadas para o controle da pandemia do Sars-Cov-2 responsável pela Covid-19, a reportagem do jornal Folha de São Paulo (BALLOUSSIER, 2020) registrou acusações, por transmissão televisiva, um pastor da igreja evangélica neopentecostal contra o "Exu Corona". Este, por sua vez, seria a entidade espiritual responsável pela doença e as consequências sociais causadas pela pandemia.

\section{A pandemônia}

Em 1667, o poeta John Milton (2016) no poema Paraíso Perdido usa a palavra pandemonium para designar o espaço que concentra a gestão do inferno, como uma espécie de palacete liderado por Satã, onde os demônios eram administrados. Quando o bispo Edir Macedo, criador da Igreja Universal do Reino de Deus usa do termo "pandemônia" para referirse à pandemia do coronavírus (MOTTA, 2020), ele mescla a ideia da existência de uma corte infernal à doença viral e suas problemáticas sociais. Como reforça Nascimento (2019, p. 187) "o diabo exerce uma função sobre um problema mundano, ou seja, o problema do mal". Diferente da visão de mundo das antigas civilizações da Mesopotâmia e de grande parte das religiosidades advindas da África, em que as deidades possuem domínios e expressões ambivalentes, não sendo completamente boas e nem más, o Deus defendido por muitas vertentes cristãs, como é o caso das igrejas neopentecostais, é uma divindade de uma só face e 
exclusivamente benevolente. Esse conceito desenvolvido primeiramente pelo Zoroastrismo, de uma constante guerra entre o bem e o mal, vai influenciar diretamente a concepção do Deus abraâmico (NASCIMENTO, 2019).

Silva (2007) alerta sobre certas convicções levantadas nas igrejas neopentecostais da existência de uma batalha entre seus fiéis e o demônio. Nesta cosmovisão, os seres cultuados nas religiões de matriz africana, principalmente Exu, são considerados a própria presença do demônio, o qual de toda maneira deve ser combatido. Infelizmente, tais pensamentos em níveis extremos levam a agressões físicas de praticantes, inclusive crianças, e de depredações a locais sagrados de cultos de origem africana. Destacando-se aqui o Candomblé, que é a religião que mais sofre intolerância religiosa no país. (SILVA, 2018)

A intolerância que forja e o poder midiático que propaga a conceitualização de um Exu Corona indica, por um lado, o processo de demonização da divindade e, por outro, a tentativa de localizar o mal-estar provocado pelo contexto social em um inimigo a ser combatido. É importante perceber a construção arquetípica que envolve a figura do Diabo como um ser que concentra em si a maldade absoluta é efeito de uma longa elaboração psicológica "por meio da mistura da ideia do mal que há nas diversas religiões (...) em que as pessoas descarregam num mito, numa figura externa, todo o mal que enxerga dentro de si (PAIVA, 2017, p.174).

Reis e Lopes (2017) reconhecem um aumento significativo das religiões protestantes uso exponencial de diversas fontes de mídias desde o final da década de 60 para propagar ideias estigmatizadas das simbologias afro-brasileira e espíritas. Fazem uso ainda de estratégias de relatos de salvação como forma de apelar à conversão religiosa. Adere-se a este arquétipo, tudo aquilo que é desprezado ou que se quer afastar de uma sociedade. São características da maioria dos demônios: agressividade, ter feições e comportamentos animalizados, não possuir beleza, transmitir medo e não ter capacidade de sentir compaixão.

É demoníaco tudo aquilo que lembra ao ser humano que ele é um animal: a excreção, o vômito, a violência, a doença, a morte, o aspecto grotesco do sexo. Ao lado disso, é divino tudo aquilo que dá ao homem a impressão de que ele pode colocar-se acima dos outros animais: o amor, a inteligência, a renúncia aos instintos básicos, o aspecto sublime do sexo (PAIVA, 2017, p.175).

Existe um risco de propagação da demonização, ao realizar uma separação entre o que é sagrado e demoníaco pela comparação entre o ser humanizado e o animal, sem considerar a cosmovisão do xamanismo americano e de religiões africanas em que as características e simbologias dos animais selvagens são sagradas e importantes no conjunto de suas liturgias. 
Percebendo todas estas conexões e sua logicidade histórica, a ideia sobre o mal e sobre os seres malignos, que aqui são chamados demônios, será moldada a partir da cultura e do tempo de cada indivíduo.

Scorsolini-Comin et al. (2020) identificaram que, durante a pandemia da Covid-19, as repercussões emocionais associadas às restrições sociais assim como às mudanças decorrente do adoecimento e morte de pessoas próximas aumentam a possibilidade de buscar na religião explicações para as consequências socioemocionais da doença. A adesão religiosa também se configura como uma estratégia capaz de promover cuidado diante de um cenário pandêmico. Isto permite pensar a religiosidade e espiritualidade enquanto elementos fundamentalmente integrados à experiência subjetiva e atuantes como uma resposta contra as incertezas frente às ameaças deste evento.

Ao associar a pandemia à figura de Exu como um demônio, a vertente neopentecostal sustenta a ótica da existência de um combate universal, um inimigo que de alguma maneira tem como objetivo a destruição dos seres humanos e que, portanto, precisa ser aniquilado. Ora, uma doença de contágio em escala mundial deveria de fato ser enfrentada por toda sociedade, seja ela qual for. Já ao "Exu Corona", além de demonstrar uma agressão direta para com um grupo religioso específico, direciona a culpa de um problema de saúde global a todos aqueles que cultuam Exu.

Neste sentido, o entendimento fenomenológico demonstra que o sofrimento é consequência da coisificação do ser em uma aparência. No contexto de intolerância religiosa, a compreensão de Exu como demônio e a desqualificação social de práticas religiosas marginalizadas incorre no risco de gerar sofrimento nos adeptos. Deve-se compreender que o humano vivencia as experiências em um contexto, sem haver possibilidade de um sujeito independente do mundo ou, ainda, a realidade sem sujeito. $\mathrm{O}$ sofrimento manifesta-se no corpo, pois todo fenômeno é pungente ao corpo (SILVEIRA et al., 2020).

\section{Exu, educação e liberdade religiosa}

No processo histórico do sistema escravagista, cabia aos negros resistência. Foi preciso esconder sua religião e história, uma vez que para o colonizador era vantajoso que os escravos perdessem sua identidade e acreditassem que haviam nascido para ser dominados. Aos olhos 
de um senhor de escravos, um bom escravo era aquele que esquecia que poderia ser livre, e melhor ainda, era aquele que sequer lembrava o que era liberdade.

Distante do modelo de sociedade projetado e forçosamente implementado por seus colonizadores, os povos da África possuem características de organização tribal, onde o rito é primordialmente voltado ao coletivo. As festas, assim normalmente chamados os rituais destinados ao culto dos orixás, foram vistas como uma algazarra de pecado e elementos que remetiam ao maligno, principalmente pela prática de sacrifícios animais, que nesta visão preconceituosa, serviam para alimentar o demônio. Vale ressaltar aqui, que a comida é peça fundamental dentro dos cultos aos orixás. A prática de imolação está diretamente ligada à fertilidade do povo e da terra. Tudo é aproveitado, e matar um animal ao espírito guardião era símbolo de entrega do que de mais valioso a comunidade possuía. Nesta crença, a benção é direito de todos sem distinções. "Os sacrifícios, quando necessários, têm o objetivo de promover a limpeza espiritual, a prosperidade, a proteção espiritual, o restabelecimento da paz e promoção da união" (SILVA, 2018, p. 58).

É de se observar que os sacrifícios de animais realizados por outras religiões, como judaísmo ou islamismo, não sejam vistos de forma tão negativa como é o caso das religiões originárias da África. Portanto, as medidas invasivas que tentam impedir estas práticas apenas dentro de religiões de matriz africana, como foi o caso do Ministério Público do Rio Grande do Sul, Brasil, em março de 2019, que tentou barrar a prática da imolação animal em cultos africanos, estão claramente repercutindo intolerâncias:

quando o ativista do direito animal enfatiza que o problema da crueldade contra os animais está no sacrifício ritualístico praticado nas liturgias afro religiosas, esse "ataque" pode se configurar uma discriminação ou intolerância visto a discrepância que há - com relação ao problema - entre o que é praticado pelas religiões afro-brasileiras e o agronegócio, a indústria da carne branca, a pesquisa de cosméticos e mesmo a utilização dos animais pela indústria do entretenimento (COELHO et al., 2016, p. 72).

O Brasil, país onde o culto de Exu recebe grande destaque devido ao número de espaços religiosos que realizam sua adoração, por muitos anos manteve os cultos afro-brasileiros como ilegais. Na constituição federativa de 1891, ocorreu a separação jurídica entre o Estado e a Igreja católica, o que permitiu o afloramento de outras práticas religiosas até o Governo Getúlio Vargas, quando novamente instituiu-se o catolicismo como religião oficial (REIS; LOPES, 2017). Apenas em 1988, com o fim da ditadura militar e a criação da Constituição Cidadã, a 
prática dos cultos de matriz africana deixou de ser enquadrado como crime. Nos demais países, principalmente por parte de devotos das religiões abraâmicas, o preconceito e a desvalorização das religiões africanas também é presente (LEISTNER; AGUIAR, 2020).

A liberdade religiosa é um dos direitos fundamentais da humanidade, como anuncia a Declaração Universal dos Direitos Humanos. Nela temos definido o direito individual e de comunidade em expressar suas crenças, realizar seus ritos, trocar de religião, acreditar ou não acreditar em determinadas teorias, ser ateu, ser gnóstico e a liberdade de se associar ou não a um grupo religioso. Permitir estas escolhas é uma das maneiras de exercício da liberdade de pensamento, e é neste espaço que o pensamento crítico se torna possível. De maneira que o indivíduo escolhe seu caminho religioso de acordo com sua moral, opções de vida, filosofias e crenças (COELHO et al., 2016).

É necessária a problematização de que na atualidade ainda existam pessoas que não se sintam seguras para expressar sua fé, sendo este, um direito básico de todo cidadão brasileiro. A liberdade religiosa é um reflexo do diálogo inter-religioso realizado com empatia e sem preconceito, pois desconhecer outras visões de mundo é um facilitador para propagação da ignorância, que em níveis elevados, causa violência. "O principal propósito da tolerância é a coexistência harmônica entre os povos e as nações com as tradições, linguagens, histórias, culturas e religiões dos demais, sem qualquer traço de limitação, intromissão, diminuição, desrespeito ou violência." (SILVA, 2018, p. 59).

$\mathrm{O}$ direito à liberdade religiosa sempre esteve como uma ferida latente na história das religiões de matriz africana no Brasil e no mundo. Ao identificar o constante aumento da narrativa sobre uma "guerra" contra a figura de Exu e seus devotos, sustentada por algumas religiões, percebe-se o quão longe a educação religiosa no Brasil vem caminhando contra o diálogo inter-religioso e a aproximação de diferentes cosmovisões. Neste sentido, o Estado laico deve assegurar as diretrizes educacionais com respeito à liberdade religiosa e à dignidade da pessoa humana. Entretanto, Junqueira e Reis (2020) assumem posição crítica ao denunciar a influência de políticos religiosos nas políticas públicas de educação a ponto de afirmar que o Estado brasileiro não é laico. Ao mesmo tempo, a formação nas escolas abre espaço para a desenvolver a diversidade religiosa e cultural de um povo e "compreender a multiplicidade de expressões religiosas coexistindo, e como elas influenciam na sociedade" (JUNQUEIRA; REIS, 2020, p. 33). 
O campo educacional deve ser visto como um dos fundamentos da construção de solução para os problemas sociais da intolerância religiosa. Nenhuma discriminação deve ser incentivada por qualquer meio de formação dos seres humanos e é responsabilidade do Estado que o direito de todo cidadão seja cumprido. Apesar da sanção da Lei 10.639/03 que instituiu a obrigatoriedade do ensino de História da Cultura Africana e Afro-brasileira no currículo da educação básica, as políticas públicas decorrentes não se mostraram coerentes entre si e expressam relações de disputa de poder. Foram identificados problemas na formação inicial e continuada de professores, bem como de livros didáticos que reiteram visões negativas sobre os negros e a cultura africana, deficiência na participação popular e representativa na agenda das políticas públicas (ALMEIDA; SANCHEZ, 2017).

Percorrer um caminho que resulte em práticas de tolerância, abertura e aceitação do diferente é um dos maiores desafios da sociedade contemporânea. Nas mais diversas esferas das atividades humanas tem-se notado o quanto a conquista da aceitação do outro é difícil, devido a um histórico de preconceitos, tais como a segregação étnica, econômica, racial e religiosa (SILVA, 2018, p. 51).

E sendo o preconceito religioso contra religiões de matrizes africanas ligado diretamente ao racismo, é ainda mais clara a responsabilidade e a necessidade de desmistificar e aproximar estas religiões da sociedade como um todo. A esfera educacional religiosa pode servir, também, como ferramenta para aprendizados quanto à sociologia, história e antropologia, valorizando a cultura negra, sua compreensão e garantia de construção identitária positiva por parte da população de origem africana.

Abre-se, então, através da educação, a possibilidade de abordar os fenômenos humanos e as realidades sociais por eles mesmos, escapando de representações estáticas ou impostas por ideais ou pela intolerância. Não existe neutralidade prévia para abordagem do tema, uma vez que o ponto de vista é produzido pelas tradições e experiências. Neste sentido, a verdade é inconstante e insegura, produzida em relação ao ser-no-mundo. Exu encarna em sua multiplicidade e imprecisão o aspecto da ontologia fundamental. Ao mesmo tempo que o ser é um conceito universal é, ao mesmo tempo, obscuro e inapreensível em sua totalidade, pois o ser não é dado, mas manifesta-se no ente e sempre em relação a outros entes (HEIDEGGER, 2004).

Ainda no âmbito educacional, quando silenciamos uma história, ou parte dela, apagamos esta história. O fenômeno religioso que abarca a demonização de Exu pretende 
portanto, qual apagamento? Enxergar Exu como demônio pode variar de acordo com a cosmovisão de cada um, mas isso não pode de forma alguma, tirar o direito de Exu de ser aquilo que é, de forma a evitar o desencanto das projeções e mal-entendidos provindos das aparências, contrastando assim essência e aparência (SILVEIRA et al., 2020).

\section{Considerações finais}

Os reflexos entre a falta de conhecimento sobre a cultura africana e os preconceitos vivenciados para com as religiões de matriz afro-brasileiras são desafios a serem superados no campo político-social. A baixa penetração da cultura negra nas produções sociais hegemônicas segue moldada pela discriminação racial e, por mais que existem muitas iniciativas como datas em homenagem aos escravos mortos durante o período escravagista ou as festas de Orixás, muitos dos hábitos e preconceitos atuais têm origem no período colonial.

Este artigo discutiu de que forma a intolerância religiosa se manifesta pela propagação da demonização de entidades de cultos minoritários, como foi o caso da associação de Exu a um demônio e responsável pela propagação da Covid-19, sem relação com a verdadeira cosmovisão de onde as culturas negras nasceram. A desmistificação de ideias construídas por grupos religiosos opressores a respeito das religiosidades afro-brasileiras também são estratégias de combate contra o racismo.

A intolerância religiosa viola os direitos e a dignidade da pessoa humana, não busca o diálogo e nem a contextualização dos elementos cultuados por religiões diferentes. Deter a ignorância religiosa, preservar a liberdade individual e coletiva deve ser um tema a ser zelado por todas as religiões, inclusive dentro do ambiente escolar, pois é com o diálogo inter-religioso que pode-se construir pontes que ligam e protejam mutuamente seus praticantes. A recorrência do processo de demonização de entidades indica a necessidade de tratar esses assuntos de tempos em tempos, uma vez que, historicamente, nossa sociedade tende a agir com radicalidade quando o assunto é a alteridade, ou seja, aquele que pensa ou é diferente.

O preceito fenomenológico da produção de sentido para ser na existência, revela a urgência em criar cuidado com a própria existência a todo instante. O cuidado exige reflexão constante sobre o sentido, por demandar a compreensibilidade do existir em todas as dimensões, das transcendentes às cotidianas (HEIDEGGER, 2004). A religião como meio de libertação dos 
seres humanos no encontro do seu próprio ser, deve agir em prol da ampliação da capacidade de união e da faceta empática do cuidado.

Uma educação religiosa libertadora deve ser construída sem apologias dogmáticas ou manipulações, incluindo educação moral, reflexões e trocas culturais. As bases educacionais podem buscar inspiração nos fundamentos fenomenológicos ao permitir o encontro entre os seres considerando os contextos em que se encontram. Ressignificar a demonização de Exu implica também na produção de novos sentidos associados a essa divindade, uma vez que, em sua própria essência, Exu é movimento e transformação. Por isso, cada vez mais é preciso investir na qualificação de profissionais a respeito das áreas de religião, em aberturas sociais para todos os tipos de crenças e ao conhecimento multicultural, a fim de garantir o bem-estar e a liberdade de expressão a todos os indivíduos igualmente.

Conclui-se portanto que o direito e a educação são caminhos satisfatórios para solucionar os problemas gerados de conflitos entre religiões diferentes quando orientados pela noção de cuidado. Através do direito se garante a liberdade religiosa e o espaço de respeito que a tolerância deve construir. A educação combate a ignorância, esta que por sua vez impossibilita a empatia, o diálogo intercultural e a contextualização do fenômeno religioso. A idealização religiosa extremista não busca a comunicação, nem entre comunidades religiosas diferentes, nem entre seus líderes e fiéis, mas sim suas delimitações. Delimitar neste contexto é impedir que o espaço a liberdade religiosa de cada indivíduo, seja ele parte do seu grupo ou não, seja respeitado.

\section{REFERÊNCIAS}

ALMEIDA, M. A. B.; SANCHEZ, L. P. Implementação da Lei 10.639/2003 - competências, habilidades e pesquisas para a transformação social. Pro-Posições, Campinas, v. 28, n. 1, p. 5580, 2017. DOI: https://doi.org/10.1590/1980-6248-2015-0141. Acesso em: 12/12/2020.

ALVARENGA, M. J. S. O Candomblé Começa na Cozinha: Alimentação, Aprendizado e Transformação. Revista Habitus-Revista do Instituto Goiano de Pré-História e Antropologia, Goiânia, v. 16, n. 2, p. 275-292, 2019. DOI: http://dx.doi.org/10.18224/hab.v16i2.5718. Acesso em: 10/12/2020.

BATISTA, B. M.; SOUZA, F. A.; PLACERES, G. Aspectos Da Intolerância Religiosa No Brasil: Dominância Política, Social e Institucional Cristã Frente à Umbanda e o Candomblé. Labirinto, Porto Velho, v. 26, n. 2, p. 123-141, 2017. DOI: https://doi.org/10.47209/15196674.v.26.n.2.p.122-141. Acesso em: 14/12/2020. 
BALLOUSSIER, A. V. 'Exu corona' e terreiro queimado escancaram intolerância religiosa na pandemia. Folha de São Paulo, Rio de Janeiro, 04 de nov. 2020. Disponível em: https://www1.folha.uol.com.br/cotidiano/2020/11/exu-corona-e-terreiro-queimadoescancaram-intolerancia-religiosa-na-pandemia.shtml. Acesso em: 12/01/2021.

COELHO, C. J. H.; OLIVEIRA, L. P. S.; DE LIMA, K. J. M. Sacrifício ritual de animais nãohumanos nas liturgias religiosas de matriz africana:"medo do feitiço" e intolerância religiosa na pauta legislativa. Revista Brasileira de Direito Animal, Salvador, v. 11, n. 22, p. 53-82, 2016. DOI: http://dx.doi.org/10.9771/rbda.v11i22.17665. Acesso em: 21/12/2020.

ELTIS, D.; BEHRENDT, S. D.; RICHARDSON, D. A participação dos países da Europa e das Américas no tráfico transatlântico de escravos: novas evidências. Afro-Ásia, Salvador, n. 24, p. 9-50, 2000. DOI: http://dx.doi.org/10.9771/aa.v0i24.20994. Acesso em: 19/12/2020.

FERNANDES, N. V. E. A raiz do pensamento colonial na intolerância religiosa contra religiões de matriz africana. Revista Calundu, Brasília, v. 1, n.1, p. 117-136, 2017. DOI: https://doi.org/10.26512/revistacalundu.v1i1.7627. Acesso em: 17/01/2021.

GEERTZ, C. A interpretação das Culturas. 1. ed. Rio de Janeiro: LTC - Livros Técnicos e Científicos Editora S.A., 1989.

HEIDEGGER, M. O ser e o tempo. Petrópolis: Vozes, 2004.

JUNQUEIRA, S. R. .A; REIS, M. V. F. Diversidade Religiosa, Laicidade Aplicado ao Ensino Religioso. Revista Labirinto, Porto Velho, v. 32, n.1, p. 25-41, 2020. DOI: https://doi.org/10.47209/1519-6674.v32.n.1.p.25-41. Acesso em: 15/04/2021.

LEISTNER, R. M.; AGUIAR, A. T. A Polêmica Da Sacralização De Animais Nos Terreiros Afro-brasileiros E Os Percursos Da Laicidade No Brasil. Revista Relegens Thréskeia, Curitiba, v. 9, n. 2, p. 113-138, 2020. DOI: http://dx.doi.org/10.5380/rt.v9i2.75593. Acesso em: 21/01/2021.

LEITE, S. A. De Guardião a Demônio: A representação da Entidade Exu na Umbanda Espiritualista. 2018. Trabalho de Conclusão de Curso em Antropologia. Instituto Americano de Arte Cultura e História, Universidade Federal da Integração Latino-Americana, Foz do Iguaçu.

MILTON, J. Paraíso Perdido. São Paulo: Editora 34, 2016.

MOTTA, N. A doença como metáfora. O Globo, online, 20 de mar. de 2020. Disponível em: https://oglobo.globo.com/opiniao/a-doenca-como-metafora-24317001. Acesso em: $17 / 04 / 2021$.

NASCIMENTO, J. E. O. A escrita acadêmica sobre o diabo: o mal ao longo dos séculos. Vozes, Pretérito \& Devir: Revista de História da UESPI, v. 9, n. 1, p. 186 - 200, 2019. Disponível em: http://revistavozes.uespi.br/ojs/index.php/revistavozes/article/view/208. Acesso em: 20/01/2020. 
NOGUEIRA, L. C. Da África para o Brasil, de Orixá a Egum: As Ressignificações de Exu no Discurso Umbandista. 2017. Tese (Doutorado em História) - Faculdade de História. Universidade Federal de Goiás, Goiânia.

OLIVEIRA, S. Psicanálise e Umbanda: A Demonização Do Exu Como Interdição Simbólica e Intolerância Religiosa. Revista Brasileira de História das Religiões, Maringá, v. 3, n. 8, p. 33-43, 2010. DOI: https://doi.org/10.4025/rbhranpuh.v3i8.30345. Acesso em: 15/12/2020.

PAIVA, L. H. R. Possessão E Exorcismo No Egito Antigo: Dados Históricos. In: COLÓQUIO DE HISTÓRIA UNICAP, n. 10, Recife, 2017, p. 1-10. Disponível em: http://encontro2014.rj.anpuh.org/resources/anais/35/1397433785_ARQUIVO_POSSESSAOE EXORCISMONOEGITOANTIGO_LUIZHENRIQUE.pdf. Acesso em: 15/01/2021.

PRANDI, R. Exu, de mensageiro a diabo. Sincretismo católico e demonização do orixá Exu. Revista USP, São Paulo, v. 50, 46-63, 2001.

. Candomblé and Time: Concepts of time, knowing and authority, from Africa to AfroBrazilian religions. Brazilian Review of Social Sciences, v. 2, p. 7-22, 2002.

Mitologia dos Orixás. São Paulo: Companhia das Letras, 2015.

PINTO, T. D ; FREITAS, B. T. D. Umbanda: Guia e Ritual para Organização de Terreiros. 7. ed. Rio de Janeiro: Eco, 1972.

REIS, M. V. F.; LOPES, T. J. S. Intolerância religiosa: um estudo sobre os casos de intolerância ocorridos no Terreiro de Candomblé Ilê Asé Ibi Olú Fonnim e com seus

integrantes na vida social. Revista Eletrônica Correlatio, São Paulo, v. 16, n. 1, 2017. DOI: https://doi.org/10.15603/1677-2644/correlatio.v16n1p137-166. Acesso em: 10/01/2021.

SARAIVA, L. A. F. De Vodum a Caboclo: Trajetória de Legbá no Terreiro de Tambor de Mina e Tereco. Revista Calundu, Brasília, v. 1, n. 1, p. 7-20, jan./2017.

SCORSOLINI-COMIN, F.; ROSSATO, L; CUNHA, V. F.; CORREIA-ZANINI, M. R.; PILLON, S. C. A Religiosidade/Espiritualidade Como Recurso No Enfrentamento Da Covid19. Revista de Enfermagem do Centro-Oeste Mineiro, São João del-Rei, v. 10, e3723, 2020. DOI: https://doi.org/10.19175/recom.v10i0.3723. Acesso em: 17/04/2021.

SILVA, N. C. F. A Ineficiência de Direito Penal na Proteção das Religiões de Matrizes Africanas Contra Crimes de Intolerância Religiosa. 2018. Trabalho de Conclusão de Curso em Direito - Faculdade de Ciências Jurídicas e Sociais, Centro Universitário De Brasília, Brasília.

SILVA, P. P. Para Além da Demonização do Guardião Exu: Elogio ao Hibridismo PósColonial em Processo de Resistências nas Religiões Afro e Brasileiras. 2017. Trabalho de Conclusão de Curso em História - Unidade Acadêmica De Humanidades, Ciências e Educação, Universidade do Extremo Sul Catarinense, Criciúma. 
SILVA, G. S. Neopentecostalismo e Religiões Afro-Brasileiras: Significados do Ataque aos Símbolos da Herança Religiosa Africana no Brasil Contemporâneo. Mana, Rio de Janeiro, v. 13, n. 1, p. 207-236, 2007. DOI: 10.1590/S0104-93132007000100008. Acesso em: 20/12/2020.

SILVEIRA, N. A.; BARROS, N. F.; RODRIGUES, B. S.; SILVA, C. C. A perspectiva fenomenológica aplicada ao estudo de caso-uma experiência de dor e sofrimento. Brazilian Journal of Health Review, Curitiba, v. 3, n. 6, 15826-15837, 2020. DOI: https://doi.org/10.34119/bjhrv3n6-017. Acesso em: 15/12/2020. 